\title{
MULTIPLE DISTRIBUTION OF THE FLUORESGENGE IN HUMAN TEETH
}

\author{
Hiroshi HORIBE, Shigeru KATSURA*, Ken FUJIMORI \\ AND MASAOKI YAMADA \\ Department of Anatomy and Institute for Biology and Experimental \\ Medicine*, School of Medicine, Tokushima University, \\ Tokushima 770
}

Received for publication July 9, 1974, and in revised form July 26, 1974

\begin{abstract}
Fluorescence components were observed in thin-sections and extracts of human teeth by fluorometric methods. The fluorescence, being multiple, distributes in all the tooth tissue in different quality and quantity. An acidsoluble fraction (with a $5 \%$ perchloric acid) well corresponds in fluorescent components of dentine, cementum and enamel, while a fraction extracted with an alkaline ethylene-glycol is different in fluorescent composites between enamel and dentine, and the composites of dentine are quite similar to those of cementum. The relative fluorescence intensity at $530 \mathrm{~nm}$ is the most intense in predentine, higher in dentine or cementum, and lower in enamel. The relative quantity seems less corresponding to ultraviolet absorption of tooth tissues.
\end{abstract}

Since Stübel et al. (1911) reported the presence of fluorescence in teeth, it is considered that various fluorescent components are in multiplicity with tooth structures. Glasser et al. (1938) indicated that fluorescence related to a mineral phase of teeth, and Hartles et al. (1953) found the fluorescence due to pyrimidine. Moreover, a pigment containing iron (Ogawa 1964), a pterydine derivative (Abe 1964) and tryptophan (Hoerman et al., 1964) were regarded as a fluorescent component. But, whether fluorescent components distributed homogeneously in different tooth tissues or not remains still obscure. The authors, therefore, studied on the distribution of fluorescence in different areas of the tooth tissue. From the present study the fluorescent components seem to be multiple in both quality and quantity and distribute heterogeneously in different areas of the tooth tissue.

\section{MATERIALS AND METHODS}

Human permanent teeth (incisor, canine and premolar), which looked intact without any caries under clinical observations, were used for the examination. Prior to examination, teeth were freed from adhering tissues.

1. Thin-sections of teeth: Removed teeth were fixed in acetone-ethanol $1: 1$ $(\mathrm{v} / \mathrm{v})$ at $4^{\circ} \mathrm{C}$ for few days. These were ground on a rough whetstone and then on a fine agate-whetstone till the slice reached in an equal thickness from $50 \mu$ to $80 \mu$. The grinding was done sagitally in the bucco-lingual direction.

2. Pulverization of tooth components: Teeth were fixed in acetone-ethanol 
$1: 1(\mathrm{v} / \mathrm{v})$ at $4^{\circ} \mathrm{C}$. These were dried in air, then each layer of the tooth components, such as enamel, dentine or cementum, was pulverized by a motor-driven dental equipment. The pulverized tissue component was washed in ethanol and next in ether, then dried in air and stored at $4^{\circ} \mathrm{C}$.

3. Fxtraction from pulverized teeth: According to Hartles et al. (1953), the fluorescent material was extracted with an alkaline ethylene-glycol containing a $3 \% \mathrm{KOH}(\mathrm{w} / \mathrm{w})$ (AEG) from each pulverized enamel, dentine or cementum. Another extraction was performed with a $5 \%$ of perchloric acid (PCA). The pulverized tissue was first extracted with AEG for 4 hours and an extract (al) was obtained. The residue was washed in ethanol and then reextracted with a $5 \%$ of PCA for 4 hours to get the second extract (p2). The extraction procedure in a reversed order was also performed. The first extract with PCA (p1) and the second extract with AEG (a2) were obtained.

4. Fluorometry: Tooth sections were immersed in a non-fluorescent glycerol in vacuo to remove air bubbles from sections and placed between a quartz slide and a cover slip and sealed with a fluid for manicuring. In measuring the fluorescence, a micro-beam of $5 \mu$ in diameter including $366 \mathrm{~nm}$ of mercury highpressure lamp was irradiated on the tissue by using a microspectrofluorometer (Nikon MF-FL, Japan). A relative fluorescence intensity (RF) of the unit optical field of $10 \mu^{2}$ was measured by wave-length scanning at $100 \mathrm{~nm} / 3 \mathrm{sec}$. according to Yamada's method (1968). In extracts from pulverized tissue excitation-and emission-spectra were measured by a fluorometer (Hitachi MPF-2A Tokyo Japan), and both spectral measurements were standardized by a certain fluorescence $\left(\mathrm{F}_{530}\right)$ of uran glass or fluorescent probe throughout the present measurement. In measuring relative ratio of the fluorescence to unit ultraviolet absorption, the same loci used for microfluorometry were measured by a microspectrophotometer (Zeiss. UMSP-1, Germany), and the absorption was represented as an optical density at $260 \mathrm{~nm}$ or $280 \mathrm{~nm}\left(\mathrm{~A}_{260}\right.$ or $\left.\mathrm{A}_{280}\right)$ according to the routine way as shown by Katsura et al. (1974).

\section{RESULTS}

\section{Fluorescence distribution in the tooth tissue}

When the tooth tissue is excited by a light of $400 \mathrm{~nm}$ transmitted through BV filter (Toshiba, Japan), a maximum fluorescence intensity at $530 \mathrm{~nm}\left(\mathrm{~F}_{530}\right)$ is emitted. So, the $\mathrm{F}_{530}$ is widely excited by a broad light of wave length from $366 \mathrm{~nm}$ to $440 \mathrm{~nm}$. As for tissue fluorescence, a relative fluorescence intensity is measured at an unit area of various tooth tissues. When the tissue thickness is variable, the fluorescence should not be compared in different tissue thickness. So, the RF of one unit area is compared with that of an unit area of neighbouring tissue, most of which is in an equal thickness. For example, a surface area of enamel $\left(E_{1}\right)$ is compared with an intermediate area $\left(E_{2}\right)$ adjacent to $E_{1}$, and $E_{2}$ is also compared with a deep area $\left(\mathrm{E}_{3}\right)$ near $\mathrm{E}_{2}$. Thus, a boader area $(\mathrm{SD})$ of dentine to enamel is compared with a deep area $(\mathrm{D})$, and $\mathrm{D}$ with predentine (PD), and a cementum area $(\mathrm{C})$ with a cellular cementum area $(\mathrm{CG})$. In this way, one pair of neighbouring tissue areas looks as well in thickness. The $F_{530}$ of enamel 

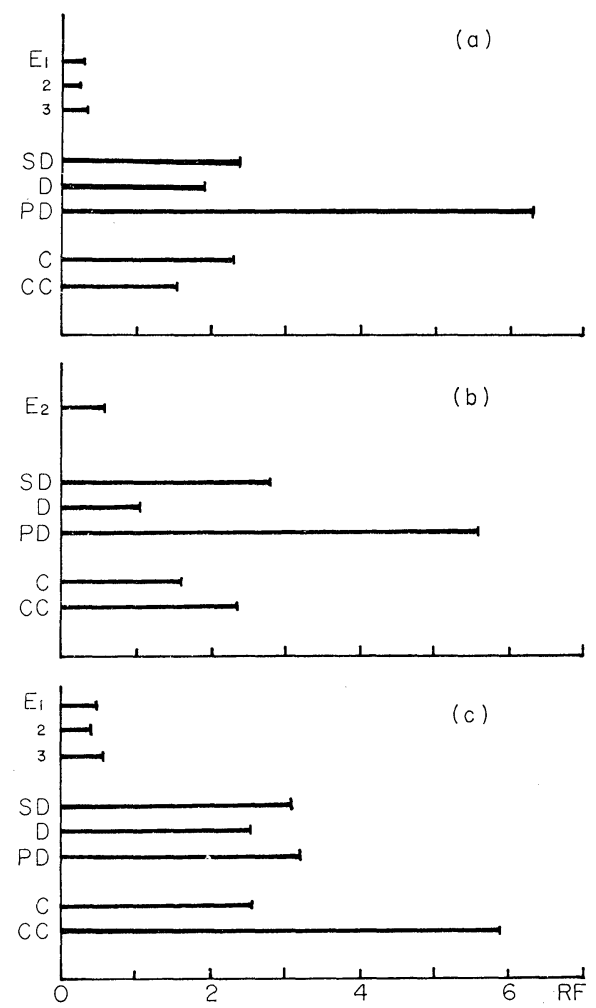

FIG. 1. Relative fluorescence intensities emitted at $530 \mathrm{~nm}\left(\mathbf{F}_{530}\right)$ are measured in 10 $\mu^{2}$ areas of various tooth structures; $\mathrm{E}_{1}$, a surface area of enamel; $\mathrm{E}_{2}$, an intermediate area of enamel; $\mathrm{E}_{3}$, a deep area of enamel; $\mathrm{SD}$, a boader area of dentine to enamel; $\mathrm{D}$, a deep area of dentine; $\mathrm{PD}$, a predentine area; $\mathrm{C}$, a cementum area; CC, a cellular cementum area. The $\mathrm{F}_{530}$ is least in enamel and much prominent in PD (case a or b) and CC (case c).
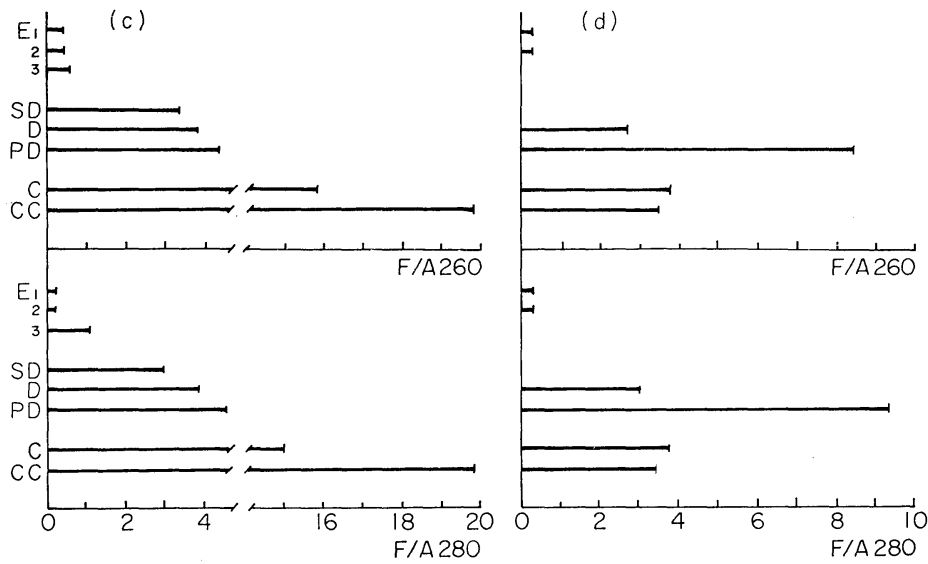

FIG. 2. Relative fluorescence per unit absorption at $260 \mathrm{~nm}$ or $280 \mathrm{~nm}\left(\mathrm{~F} / \mathrm{A}_{260}\right.$ or $\left.\mathrm{F} / \mathrm{A}_{280}\right)$ is compared between different tooth areas. The values in dentine and cementum are higher than those in enamel. The values in $\mathrm{C}, \mathrm{CC}$ and $\mathrm{PD}$ are much higher than any others. 
is less in quantity (less than one fifth) than that of dentine or cementum. A boader area of the enamel $\left(E_{3}\right)$ appears to be more fluorescent than any other enamel areas (Fig. 1). The RF of predentine (PD) occasionally becomes two times higher than the other dentine areas (SD and D) (Fig. la, b). In general the fluorescence of cementum is as high as in dentine and cellular cementum (CG) often becomes higher than that of non-cellular cementum (C) (Fig. 1c).

Those differences may due to variable distribution of the RF in tooth tissues. Further to compare the difference, a relative fluorescence per unit absorption at $260 \mathrm{~nm}$ or $280 \mathrm{~nm}\left(\mathrm{~F} / \mathrm{A}_{260}\right.$ or $\left.\mathrm{F} / \mathrm{A}_{280}\right)$ was calculated as shown in Fig. 2c, d. Since the values are independent to tissue thickness, the value is well comparable each other. The RF of dentine is higher than that of enamel and the RF of predentine occasionally exceeds than those of all other regions (Fig. 2d). The RF in cementum (C) appears occasionally much higher, especially in that of cellular cementum (Fig. 2c). Thus, the $F / A_{260}$ and $F / A_{280}$ make clear the difference of $R F$ distribution in different tissues. This may be due to absence of a positive relationship between fluorescent substance and absorbing substance in quantity.

\section{Multiplexity of the fluorescence}

Furthermore to qualify the tooth fluorescence, fluorescent fractions were extracted. The enamel layer was roughly separated from the tissue layer of dentine or cementum by a dental equipement, and fluorescent components were extracted from each pulverized tissue layer. The fluorescence distribution was not so well determined in the extracts as in the tooth tissue. On extract with AEG excitation spectra were observed when emitted at $530 \mathrm{~nm}$ (Fig. 3a). In the spectra relative fluorescence distributes widely from $300 \mathrm{~nm}$ to $500 \mathrm{~nm}$ and the excitation is well corresponding to extracts from both dentine and cementum. But, an extract from enamel reveals another prominent peak near $270 \mathrm{~nm}$, while this excitation is only a trace in the extract from dentine or cementum. To the residue extracted with a 5\% PCA, whereas a PCA-soluble fraction is removed, AEG is used for a successive extraction (Fig. 3b). In this case the fluorescent component of acid-insoluble fraction may be separated from that of acid-soluble one. The emission of enamel excited at $270 \mathrm{~nm}$ is resistant to extract with PCA rather than the emission excited near $400 \mathrm{~nm}$. A PCA-soluble fluorescence is generally found in all of enamel, dentine and cementum (Fig. 3c), and spectral patterns of all the tissue are corresponding to each other as shown in Fig. 3a, in which a broad peak near $400 \mathrm{~nm}$ with a shoulder at about $470 \mathrm{~nm}$ is shown.

From these data, the excitation spectral profile, being multiple, consists of two components, one is generally distributed in all tooth tissues but prominent in dentine and cementum, and the other (excited near $270 \mathrm{~nm}$ ) is mostly linked to the enamel layer. So that, the fluorescence characteristic is most clearly demonstrated when these extracts are excited at $270 \mathrm{~nm}$ (Fig. 4abc). In comparing the relationship between the emission (Fig. 4a) and excitation spectra (Fig. 3a), a main fluorescence peak is observed near $310 \mathrm{~nm}$ in dentine and cementum, but near $340 \mathrm{~nm}$ in enamel in which another peak is overlapped near $540 \mathrm{~nm}$. It seems clear that there is difference in quality of fluorescence components between enamel and dentine. In the fluorescent extract with AEG after a PCA-soluble component is removed, an emission spectrum (Fig. 4 b) resembles a mirror image to the excitation 

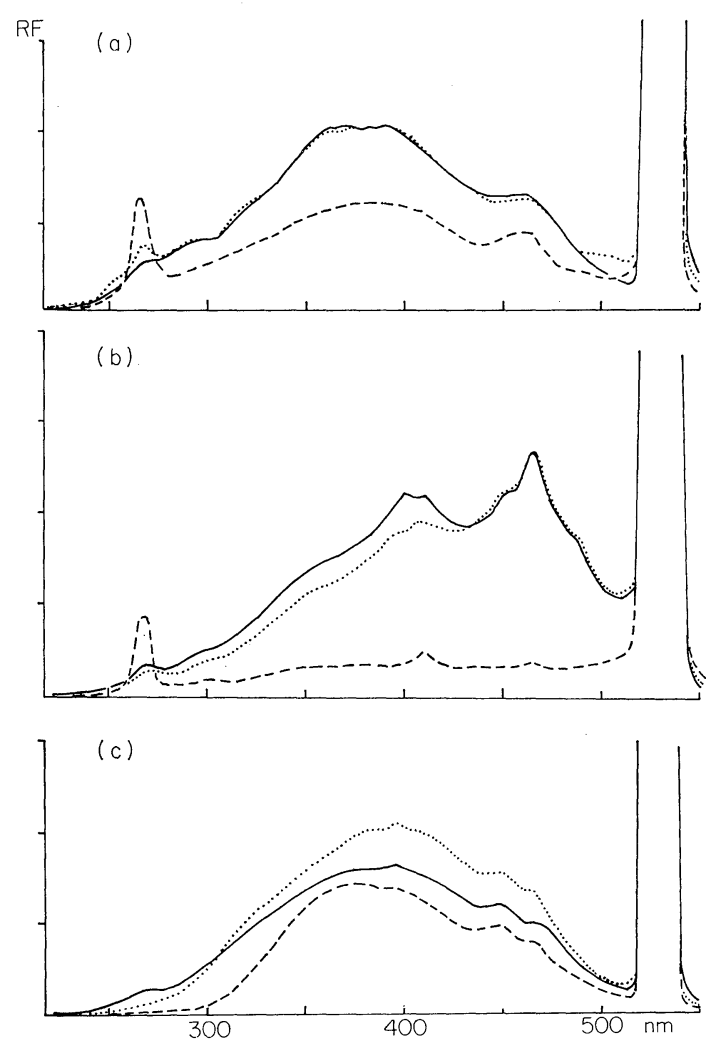

FIg. 3. Excitation spectra emitted at $530 \mathrm{~nm}$ in extracts from different tooth tissues: - dentine layer, ...... cementum layer, -.....- enamel layer.

(a) extract (a1) with AEG, (b) extract (a2) with AEG after extracted with PCA, (c) extract (p1) with PCA. Three extracts show a similar spectral pattern in (c), while enamel extract differs from the others in (a) and (b).

spectrum (Fig. $3 \mathrm{~b}$ ), whereas the emission is multiple revealing three components near $350 \mathrm{~nm}(1), 440 \mathrm{~nm}(2)$, and $540 \mathrm{~nm}$ (3). In the dentine and cementum the (1) and (2) are prominent, but the (3) is faint. While in the enamel the (3) is prominent and the (2) is reduced. In the fluorescent extracts with a 5\% PCA, however, both the (1) and (2) are not detectable at all in enamel (Fig. 4c).

\section{DISGUSSION}

Stübel et al. (1911), Benedict (1928), Glasser et al. (1938) and Yamaguchi (1942) reported the presence of the fluorescence in teeth and Hartles et al. (1953), Pincus (1953), Laurila and Mancewicz. (1960) further studied the nature of fluorescence. They reported that the fluorescence looked blue or yellowish blue and more intense in dentine and cementum. Glasser and Fonda (1938) postulated the fluorescence related to the mineral phase of teeth. Hartles et al. (1955) reported an intimate relation to pigment containing iron. Hoerman et al. (1964) found the 

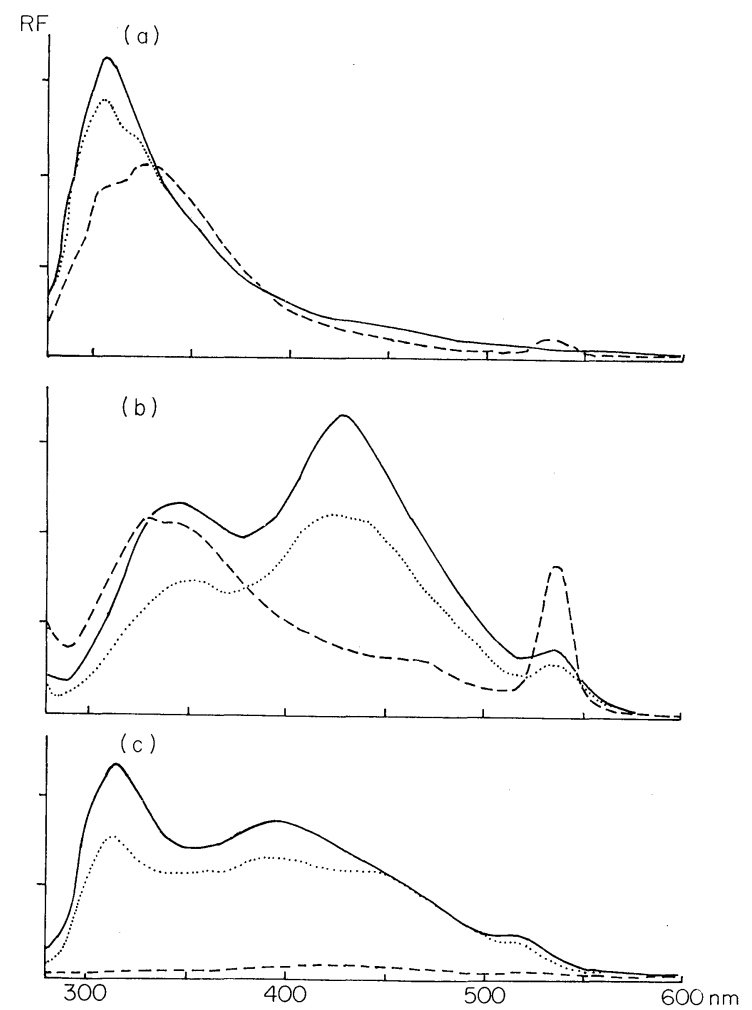

Fig. 4. Emission spectra excited at $270 \mathrm{~nm}$ in such extracts from different tooth tissues as in Fig. 3.

PCA-soluble fluorescent components are rich in dentine and enamel but poor in enamel. $\quad F_{\text {max }}$. of extracts (a1) is observed near $310 \mathrm{~nm}$ as shown in (a). Emissions of extracts (a2) show multiple patterns which resemble (p1) in dentine and cementum and (a1) in enamel, respectively.

fluorescence related to tryptophan and Abe et al. (1964) pointed the fluorescence due to pterydine derivatives. The discrepancy of these reports on the fluorescence may be due to multiplexity of the fluorescence in quality. No details have been studied by microfluorometry. When the tooth tissue is excited at a filtered beam of $5 \mu$ involving $366 \mathrm{~nm}$ mercury line, the Fmax. is observed at $530 \mathrm{~nm}$ in every layer of enamel, dentine or cementum. Besides, the relative fluorescence intensity $\left(\mathrm{RF}_{530}\right)$ varies among tissue species and even among different areas of the same tissue species. These differences are studied in relating to ultraviolet absorption of tooth tissues. There found less correlation between the fluorescence and the absorption at $260 \mathrm{~nm}$ or $280 \mathrm{~nm}$. The tissue area, with a higher absorption is not so much intense in the fluorescence. In respect to pyrimidine reported by Hartles et al., the ultraviolet absorption of pyrimidine is not identified in tooth tissues in situ, and the Fmax. does not reveal in $530 \mathrm{~nm}$ at all. On the emission spectrum of tooth tissues excited at $270 \mathrm{~nm}$, the fluorescence widely ranges from $300 \mathrm{~nm}$ to $400 \mathrm{~nm}$, which may involve the emission from thymine postulated by 
Hartles et al. Any way, it seems difficult to qualify the emission at the tissue level. On the fluorescence found in an acid-soluble fraction (a 5\% PCA extract) from teeth, a multiple excitation pattern is observed from $300 \mathrm{~nm}$ to $400 \mathrm{~nm}$, which is well corresponding in every tissue of teeth. This may suggest that similar components of the excitation are proposed in all the tooth tissues. As fluorescence components are simultaneously removed with a mineral phase of the tooth, the fluorescence seems to correspond to the component reported by Glasser (1938), and to relate to EDTAdecalcifying process reported by Onikubo (1957). In the extract with an alkaline ethylene-glycol recommended by Hartles et al. (1953), the fluorescence profile is almost similar between dentine and cementum, but is different between dentine and enamel. The difference becomes remarkable in the fraction after removed an acid-soluble fraction from the enamel.

A prominent excitation occurs at $270 \mathrm{~nm}$, in which an emission consists of three components shown near $350 \mathrm{~nm}$ (1), $440 \mathrm{~nm}$ (2) and $540 \mathrm{~nm}$ (3). Relative emissions of (1) and (2) is much higher in dentine and cementum than in enamel. But an emission of (3) is much intense in enamel than that of (1) or (2). From these findings it is assumed that another fluorescence appears in the fraction removed an acid-soluble fraction and that the fluorescence is different in its composition between enamel and the other tissue. Besides, the predentine layer pocesses much $\mathrm{F}_{530}$ fluorescence, suggesting a positive correlationship between $\mathrm{F}_{530}$ and regenerating activity of the dentine layer. This kind of heterogeneity of the fluorescence is also seen between cementum and cellular cementum.

From reports by Hartles, Ogawa, Hoerman and Abe, the fluorescence seems due to different components of fluorescent material and to different tissue composites. Moreover, a pathological injury such as tooth caries may remove the fluorescence in relating to ultraviolet absorption as suggested by Pincus (1953). Thus, the variety of tooth fluorescence may appear as a change in fluorescent color described by Katayama (1956). But multiplexity is still in problem from the theoretical basis of fluorescence.

\section{AGKNOWLEDGEMENT}

The authors like to express their thanks to Prof. H. Tsutsui, the Department of Oral Surgery, Tokushima University for a gift of human teeth.

\section{REFERENCES}

1. Abe, Y., Goto, M., Kohata, T., Kinoshita, M. and Suzuki, K.: Fluorescent material from human teeth. Nihon Univ. Dent. J. (Tokyo) 38; 411, 1964.

2. Benedict, H. C.: A note on the fluorescence of teeth in ultraviolet rays. Science 67; 442, 1928.

3. Glasser, J. and Fonda, G. R.: The fluorescence of double salts of calcium phosphate. $J$. Am. Chem. Soc. 60; 722, 1938.

4. Hartles, R. L. and Leaver, A. G.: The fluorescence of teeth under ultraviolet irradiation. Biochem. J. 54; 632, 1953.

5. Hartles, R. L. and Leaver, A. G.: The identification of pyrimidines in the fluorescing reactions of the teeth of the sperm whale. J. Dent. Res. 34; 820, 1955.

6. Hoerman, K. C. and Mancewicz, S. A.: Fluorometric demonstration of tryptophan in dentine and bone protein. J. Dent. Res. 43; 276, 1964. 
7. Katayama, R. et al.: Fluorescence microscopic observations on hard tissues of teeth (Japanese). Jap. J. Oral Hygiene 5; 147, 1956.

8. Katsura, S., Horibe, H., Yoshida, Y. and Yamada, M.: Ultraviolet absorption of human teeth as revealed by microphotometry. Acta histochem. cytochem. 7;329, 1974.

9. Laurila, U. R. and Mancewicz, S. A.: Isolation and partial fractionation of fluorescent material from human teeth. J. Dent. Res. 39; abstr. at 38th gen. meet. 1960, p. 714.

10. Ogawa, M.: Studies on a pigment in the teeth. Nichidai Ishi (Tokvo) 19; 703, 1960.

11. Onikubo, H.: EDTA-decalcifying process of hard tissues observed with ultraviolet absorption and fluoro-metry. J. Jap. Stomatol. Soc. (Tokyo) 24; 230, 1957.

12. Pincus, P.: Dental caries: Early stages. Examination of teeth by ultraviolet rays. Austral. J. Dent. 57; 199, 1953.

13. Stübel, H.: Die Fluoreszenz tierischer Gewebe in ultraviolettem Licht. Pfü̈. Arch. ges. Physiol. 142; 1, 1911.

14. Yamada, M.: A rapid recording microfluorometer and its application for the study of nucleic acid-dye binding. abstr. at 3rd Int. Congr. Histochem. and Cytochem. 1968, p. 229.

15. Yamaguchi, H.: Fluorescence microscopic studies in teeth. Acta Inst. Anat. Niigata 14; 1, 1942. (in Japanese) 